\title{
The impact of mobile technologies on new graduate nurses' perceived self-efficacy and clinical decision making: A report from a longitudinal study in Western Canada
}

\author{
Monique Sedgwick*1, Olu Awosoga ${ }^{1}$, Lance Grigg ${ }^{2}$ \\ ${ }^{1}$ Faculty of Health Sciences, University of Lethbridge, Lethbridge, Canada \\ ${ }^{2}$ Faculty of Education, University of Lethbridge, Lethbridge, Canada
}

Received: September 12, 2017

DOI: $10.5430 /$ jha.v6n6p28
Accepted: November 3, 2017

Online Published: November 10, 2017

\begin{abstract}
Healthcare environments require practitioners to competently and independently collect pertinent data, select appropriate key resources, prioritize information, solve problems, and make sound clinical decisions. The steady increase of health-related information implies a need for useful, practical Information and Communication Technology (ICT) tools that easily provide nurses' access to accurate evidence-based information. The purpose of this study was to explore the impact of using mobile technologies at the point of care on new graduates' perceived clinical decision making ability and associated level of self-efficacy over time. A longitudinal quasi-experimental pre-test/post-test design was used. A trend in the findings of this small study suggests that over time, using mobile technologies at the point of care did not enhance the participants' perceived clinical decision making ability or self-efficacy in clinical decision making. Notwithstanding, the use of mobile technologies in the practice setting is wide spread. It, however, may be that the transition from student to graduate nurse is a significant enough event that seriously limits the useful influence of mobile devices and their associated applications on clinical decision making ability and self-efficacy.
\end{abstract}

Key Words: Mobile technologies, Self-efficacy, Clinical decision making, Nursing students, Nurses, New graduates

\section{INTRODUCTION}

A major goal of any nursing program is to produce practice ready graduates who have strong clinical decision-making skills. Mobile technologies are rapidly being adopted by health care professionals ${ }^{[1]}$ because of their perceived benefits. They also have the potential of becoming invaluable in supporting new nurse graduates in their ability to engage in timely and effective clinical decision making. Moreover, the steady increase of health-related information implies a need for useful, practical Information and Communication Technology (ICT) tools that easily provide nurses with access to accurate evidence-based information. While most health care agencies provide nurses with access to computers, these may or may not have Internet access and are rarely available at the patient's bedside. Consequently, nurses and nursing students are turning to mobile devices as a source of up-to-date health-related information. ${ }^{[2]}$ However, little is known about how mobile technologies over time impact

*Correspondence: Monique Sedgwick; Email: Monique.sedgwick@uelth.ca; Address: Faculty of Health Sciences, University of Lethbridge, Lethbridge, AB., T1K 3M4, Canada. 
new graduate nurses' clinical decision making ability and associated self-efficacy. The findings of this study provide healthcare institutions and nursing programs with beginning evidence to ground their deliberations concerning the role of mobile technologies in nursing practice and education.

\subsection{Theoretical concepts}

For this study, clinical decision making is defined as the "reflective, concurrent, creative, and critical thinking processes" embedded in nursing practice. ${ }^{[3]}$ Clinical decision making also involves knowing what information about the client is needed, how to collect and organize that information and identify interventions that will help clients achieve desirable outcomes. Nurses need to know how to efficiently evaluate the plan of care when working with a client, and to decide how to best help him/her reach his/her desired level of health. ${ }^{[3]}$ Self-efficacy is defined as the belief in one's capabilities to organize and execute the action required to manage prospective situations. ${ }^{[4,5]}$ As a dynamic, changeable self-evaluation, self-efficacy is dependent on several domains such as appearance, social approval and especially in university students, school competence. ${ }^{[6]}$ Self-efficacy is an important indicator of future practice and is often related to academic success since it is both the cause of academic persistence and the result of accomplishment. ${ }^{[4]}$

\subsection{Literature review}

Mobile technologies such as laptop computers, ipads, ipods, tablets and cellular telephones have become an integral part of health care environments. ${ }^{[7]}$ While mobile devices (also referred to as handheld devices or personal digital assistants [PDA]) have become ubiquitous in our personal lives, nurses are also increasingly using mobile technologies in the workplace. ${ }^{[-9]}$ According to some nurses who work in acute care and long-term care facilities, community settings, primary care programs and rural practice settings, using mobile devices in their practice setting has enhanced their skills and awareness of research evidence which has assisted them in their clinical practice. ${ }^{[10,11]}$ Still other nurses who use mobile devices report spending less time completing unnecessary paperwork $^{[12]}$ which increases patient safety ${ }^{[13]}$ including during blood product administration. ${ }^{[14,15]}$

Mobile technologies have also influenced undergraduate nursing students' learning experience. For example, not only can undergraduate nursing students access necessary information independent of place and time by using mobile devices, ${ }^{[16]}$ they also are able to access a wide variety and wealth of information. ${ }^{[17]}$ Indeed, in a pre-posttest comparative study Miller and colleagues ${ }^{[18]}$ found that PDA were effective in enhancing nursing students' ability to retrieve reference materials. Furthermore, mobile devices seem to improve students' self-efficacy by facilitating quick access to drug and medical information ${ }^{[16,19]}$ making them more effective in the provision of nursing care. ${ }^{[20,21]}$ Consequently, mobile devices may help students provide safer patient care and improve quality of care since encounters with patients can be more thorough since they do not have to leave their patients to look up information. ${ }^{[16]}$

Notably, there are extensive and limiting barriers to using mobile technologies such as lack of access to the Internet, cost, policy limitations, and compatibility. ${ }^{[22]}$ However, in keeping with Guo, Watts, and Wharrad's conclusions ${ }^{[23]}$ from their integrative review, students find handheld devices useful for clinical practice. ${ }^{[24]}$ Hence, while learning to use mobile technologies has the potential to increase students' stress levels, ${ }^{[25]}$ context-aware mobile learning systems have the potential to enhance students' learning outcomes by decreasing the learning pressure at the point of care. ${ }^{[26]}$

Despite the many reported advantages of using mobile technologies in the practice setting, little is known about how these technologies influence the quality of students and nurses' clinical decision ability. In a comparative descriptive study with senior undergraduate nursing students completing a 14 week clinical course, students' questioning practice, propensity to seek answers to questions, and articulation of their rationale for interventions was measured. ${ }^{[27]}$ The author concluded that it was inappropriate to claim that PDA resources reduce medication errors and healthcare costs, improve diagnostic reasoning, or promote the development of effective treatment protocols since there were no statistically significant differences in clinical reasoning between PDA users and non-PDA users. In another comparative study, researchers found undergraduate nursing students who used mobile technologies at the point of care were more likely to use strategic and deliberative thinking skills, and rely less on algorithmic thinking than students who did not use mobile technologies. ${ }^{[28]}$ However, there is conflicting evidence pertaining to the impact of using mobile technologies on clinical decision making and reasoning. As well, no studies were found that explored the impact of using mobile technologies over time as students transition into their new graduate role. This gap makes this particular study especially relevant to hospital administrators as well as nursing programs.

\subsection{Hypotheses}

The following two hypotheses guided this study: (1) New graduates who use mobile technologies at the point of care will demonstrate higher levels of clinical decision making ability over time. (2) New graduates who use mobile technologies at the point of care will demonstrate higher levels of 
self-efficacy in their clinical practice over time. The variables of clinical decision making and self-efficacy were rooted in the descriptions of the theoretical concepts described earlier in this paper. We have assumed that: (1) mobile technologies support clinical reasoning and; (2) new graduates feel comfortable using mobile technologies in the practice setting.

\section{METHOD}

A quasi-experimental longitudinal pre-test/post-test design was used. After an in-class presentation to students completing their final clinical practicum was completed by a research assistant, and students interested in participating in the study were identified, a mobile application (PEPID Professional Suite) was downloaded on their mobile cellular device. A brief orientation to the application (app) was provided to the participants by the research assistant. A link to an online tutorial was also provided. This particular app is a native app which means that it does not require Internet access to use. It is also comprehensive having clinical/medical information for over 2,300 health conditions, nursing diagnoses, medication and intravenous compatibility, recently published research, laboratory and diagnostic information, and patient teaching information. Participants were instructed to use the app at the point of care during their regularly scheduled clinical shifts. The final clinical practicum was 350 hours long which allowed the students to become familiar and comfortable with the app.

The participants were also asked to complete and return a questionnaire at specific times. Participants were sent a reminder via email and/or text messaging by the study research assistant to complete the questionnaire. Questionnaires were most frequently returned via email. Data were collected over a 10 month period at four different times: at the beginning of the participants' final clinical practicum in their nursing program and prior to having the app downloaded on their mobile device; end of the practicum; 3 months post-graduation and; 6 months post-graduation. Ethics approval was received from the Human Subject Research at the researchers' university (protocol \# 2015-023). All data were managed using Tri-Council Policy Statement II guidelines. Study participants provided written consent at the start of the study, prior to data collection. Participants were assigned code numbers for tracking purposes and to maintain confidentiality.

\subsection{Questionnaires}

Critical and creative thinking are essential cognitive capacities nurses need to possess if they are to make knowledgeable, confident and effective decisions in the provision of high quality patient care. Tested for reliability and validity on 111 participants, the "Clinical Decision Making in Nurs- ing Scale" (Cronbach's alpha 0.83) ${ }^{[29]}$ assesses and evaluates clinical decision making in nursing. The instrument consists of 40, 5-point Likert-type response items. The scale assesses four categories of decision-making: (1) search for alternatives or options; (2) canvassing of objectives and values; (3) evaluation and re-evaluation of consequences and; (4) search for information and unbiased assimilation of new information. This questionnaire has appeared in at least 90 published studies ${ }^{[30]}$ suggesting that it is a reliable tool for measuring perceived clinical decision making ability.

Based on prior quantitative and qualitative research, the "Clinical Effectiveness and Evidence Base Practice Questionnaire" (Cronbach's alpha 0.87) ${ }^{[31]}$ is comprised of three subscales: attitudes toward, knowledge of, and use of evidencebase practice. Each subscale has good internal consistency: ${ }^{[32]}$ attitudes toward EBP (0.79), knowledge of EBP (0.91) and, use of EBP (0.87). The questionnaire is comprised of 24, 7 point Likert-type response items ranging from 1 (Poor/Never) to 7 (Best/Frequently). Use of this questionnaire for this study was relevant given that evidence-based practice attempts to bridge the gap between research and practice $^{[33]}$ and is the cornerstone of effective professional nursing practice.

The "Self-efficacy in Clinical Performance" (Cronbach's alpha 0.96$)^{[5]}$ was used to collect data pertaining to one's perception of ability to perform competently and effectively in a particular task or setting. ${ }^{[34]}$ Feeling confident in one's ability to make clinical decisions is foundational to effective professional nursing practice. The questionnaire is comprised of 37, Likert-type response items. There are four subscales: assessment, diagnosis and planning, implementation, and evaluation. Internal consistency of the four subscales ranges from 0.90 to 0.92 . Reliability showed stability of the instrument with a correlation of 0.94 .

\subsection{Participants}

Undergraduate nursing students completing the final clinical course at the researchers' university were invited to participate in this quantitative study. Using convenience sampling, at the beginning of the study, 25 students volunteered. Only 12 participants fully completed and returned the questionnaires at each of the four data collection points. Reasons for withdrawal from the study most frequently were personal in nature while one participant did not download the app on his/her mobile device.

Of the twelve participants, $50 \%$ of them were between 20 and 25 years of age and female (67\%). Student clinical placements occurred in emergency units, intensive care units, and medical and surgical units in a tertiary level acute care 
hospital. Responses to questions that would help determine level of comfort and use of mobile devices indicate that the participants in this study had been using a mobile device on average for 8.7 years $(S D=4.52$, Median $=9.75$, Mode $=10$ ) and were comfortable using their device for different purposes. For example, all of the participants reported using their mobile device to make telephone calls, text messaging, and accessing the Internet, email and social networks. The majority of the participants $(92 \%)$ used their mobile device to access course materials and prepare for their clinical experiences (83\%). At the three and six month data collection point, all of the participants were employed either full or part-time in acute care facilities across Western Canada.

\subsection{Data analysis}

Data were analyzed using the Statistical Package for the Social Sciences (SPSS) v.22. A general linear model (GLM) repeated measures ANOVA was used to test changes in participant responses over time. G*Power 3.1.9.2 software was used to complete the sensitivity analysis for this study. ANOVA repeated measures, within factors $\mathrm{F}$ tests with $\alpha=$ 0.05 , Power $(1-\beta)=0.85$, sample size $=12$, resulted in an moderate effect size of 0.38 and a critical $F=2.89$. Due to the small sample size $(n=12)$, we focused on the descriptive statistics and significant trends over time.

\section{Results}

Table 1 presents the means and standard deviations of participant responses to questions where a statistically significant difference was noted over time by GLM repeated-measures ANOVA testing. These results should be viewed with some caution due to the small sample size $(n=12)$. The reference time period for each question is indicated with reference category. It should be noted that in some cases significant changes in scores occur between individual pairs of time periods rather that overall between time one and time four. That being said, mean scores were consistently lower at Time 4 suggesting a trend in lower perceived clinical decision making ability and self-efficacy over time.

Table 1. Significant findings over time with repeated measures ANOVA testing

\begin{tabular}{|c|c|c|c|c|c|c|}
\hline \multirow{2}{*}{ Question } & \multicolumn{4}{|c|}{ Time Period, M (SD) } & \multirow{2}{*}{$\begin{array}{l}\text { Statistical Test } \\
\mathbf{F}(1,11)\end{array}$} & \multirow{2}{*}{$\begin{array}{l}\text { Partial } \\
\text { Eta }^{2}\end{array}$} \\
\hline & 1 & 2 & 3 & 4 & & \\
\hline \multicolumn{7}{|c|}{ Considering your practice in relation to an individual client's care, how often have you done the following in response to a gap in your knowledge? } \\
\hline $\begin{array}{l}\text { EBP2: Tracked down relevant evidence once you have } \\
\text { formulated the question }\end{array}$ & $2.41(0.51)^{\alpha}$ & $1.83(0.39)^{*}$ & $2.09(0.67)$ & $1.91(0.29)^{*}$ & $5.69^{\beta}$ & 0.34 \\
\hline $\begin{array}{l}\text { EBPQ7: New evidence is so important that I make the } \\
\text { time in my clinical schedule to keep up to date with all } \\
\text { the new evidence }\end{array}$ & $3.25(1.06)^{\alpha}$ & $3.25(0.87)$ & $2.50(1.17)$ & $2.67(1.07)^{* *}$ & $16.84^{\beta}$ & 0.61 \\
\hline $\begin{array}{l}\text { EBPQ24: How would you rate your ability to } \\
\text { disseminate new ideas about care to peers }\end{array}$ & $3.67(0.77)^{\alpha}$ & $3.58(0.51)$ & $3.33(0.89)$ & $3.00(0.43)^{*}$ & $6.80^{\beta}$ & 0.38 \\
\hline \multicolumn{7}{|l|}{ I am confident that in the clinical setting, I am: } \\
\hline $\begin{array}{l}\text { SEQ1: able to collect significant data by physical } \\
\text { assessment }\end{array}$ & $2.08(0.66)^{\alpha}$ & $1.92(0.29)$ & $1.67(0.49)^{*}$ & $1.67(0.49)^{*}$ & $7.62^{\beta}$ & 0.41 \\
\hline $\begin{array}{l}\text { SEQ12: able to set patient problem priorities based on } \\
\text { the patient's health condition }\end{array}$ & $2.42(0.51)^{\alpha}$ & $2.00(0.60)$ & $2.08(0.67)$ & $1.91(0.51)^{*}$ & $5.01^{\beta}$ & 0.31 \\
\hline $\begin{array}{l}\text { SEQ20: able to develop a patient's daily care plan based } \\
\text { on priorities }\end{array}$ & $2.17(0.72)$ & $1.92(0.67)^{\alpha}$ & $2.00(0.85)$ & $2.50(0.67)^{*}$ & $6.22^{\gamma}$ & 0.36 \\
\hline $\begin{array}{l}\text { SEQ24: able to carry out patient care plans based on } \\
\text { available resources }\end{array}$ & $2.08(0.67)$ & $1.67(0.49)^{\alpha}$ & $1.83(0.58)$ & $2.00(0.60)^{*}$ & $9.14^{\gamma}$ & 0.45 \\
\hline $\begin{array}{l}\text { SEQ34: able to find the point of breakdown in the } \\
\text { nursing process }\end{array}$ & $3.17(0.83)^{\alpha}$ & $2.33(0.89)^{* *}$ & $2.58(1.00)^{*}$ & $2.67(0.78)$ & $\begin{array}{l}22.56^{\gamma} \\
7.30^{\delta}\end{array}$ & $\begin{array}{l}0.67 \\
0.40\end{array}$ \\
\hline $\begin{array}{l}\text { SEQ35: able to decide about continuing or modifying } \\
\text { the care plan based on patient prognosis }\end{array}$ & $2.92(0.79)^{\alpha}$ & $2.50(0.80)$ & $2.42(1.00)$ & $2.25(0.62)^{* *}$ & $25.00^{\beta}$ & 0.69 \\
\hline $\begin{array}{l}\text { SEQ36: able to decide about changing outcomes based } \\
\text { on changing prognosis }\end{array}$ & $2.83(0.71)^{\alpha}$ & $2.33(0.78)^{*}$ & $2.33(0.96)$ & $2.08(0.51)^{*}$ & $9.25^{\beta}$ & 0.46 \\
\hline
\end{tabular}

Note. $\mathrm{M}=$ Mean; $S D=$ Standard Deviation; ${ }^{a}$ Reference Category; ${ }^{\beta}$ Linear Polynomial Contrast; ${ }^{\gamma}$ Quadratic Polynomial Contrast; ${ }^{8}$ Cubic Polynomial Contrast; $p<.05 ;{ }^{* *} p<.01 ;{ }^{* * *} p<.001$

\section{DISCUSSION}

The purpose of this study was to explore the impact of using mobile technologies on perceived clinical decision making ability and perceived self-efficacy in making clinical decisions over time as students' transitioned into their new graduate role. Although using mobile devices and their associated apps have the potential to enhance users' ability to make sound clinical decisions and positively impact patient outcomes, the findings of this study suggest that the transition from student to graduate nurse is a significant event and as a result, their level of influence on perceived clinical decision making ability and confidence is limited. This is consistent 
with other studies that have provided us with ample evidence that the first 18 months of a nurses' career trajectory is inundated with such difficult challenges to warrant being described as transition shock. ${ }^{[35]}$ Indeed, in a review of the literature of what is known about graduate nurses' experience as they transition into practice, Gardiner and Sheen ${ }^{[36]}$ suggest that new graduates experience extensive stress, feel overwhelmed, unprepared, and lack knowledge and skill to perform adequate patient care.

The findings of this study also suggest that engaging in more advanced skills like collecting significant physical assessment data or setting problem priorities is a challenge for these new graduates. This is consistent with Boychuck Duchscher's work ${ }^{[37]}$ where she suggests that prior to 6 months post-graduation, new graduates have limited capacity for multitasking and higher-order decision making that requires coalescing of various sources of information and information complexity. It may not be surprising then, that using mobile technologies at this stage in their transition appeared to be ineffective in deepening the study participants' perceived level of clinical decision making ability.

Given that nurses need specific knowledge and competencies to become successful, new graduates must be supported in strengthening and deepening their nursing skills and critical thinking ability. ${ }^{[38]}$ Mentorships, internships, residency programs and preceptorships have been frequently suggested as strategies that might support new graduates in their transition. Duclos-Miller ${ }^{[38]}$ also suggests that orientation models need to include time for new graduates to practice their clinical decision making skills. Moreover, support from senior nurses and nurse educators might include using such strategies as the think-aloud method ${ }^{[39,40]}$ and deconstructing patient events with the purpose of reconstructing these events using different courses of action and discussing the consequences of various decisions.

The findings from this study also suggest that having an extensive resource in the palm of their hand that can be used anywhere and anytime, did not positively influence participants' perceived self-efficacy in clinical decision making ability. Perceived low levels of self-efficacy is consistent with the literature where new graduates express having low levels of confidence. ${ }^{[35,36]}$

For the participants in this study, self-efficacy in clinical decision making might have been influenced by the level of patient acuity and recognition that they lacked practice experience and confidence to navigate complex and dynamic clinical environments. All of the participants in the study worked in clinical environments where patients were frequently unstable with complex healthcare needs (for exam- ple emergency departments and Intensive Care Units). Since new graduates think and act differently than more experienced nurses in such environments, ${ }^{[41]}$ it is not surprising that having mobile technologies at their fingertips did not enhance participants' level of self-efficacy. Indeed, confidence in the depth and breadth in critical thought and clinical judgement one possesses comes with time and experience. ${ }^{[35,42-45]}$ Building confidence in perceived abilities to complete complex tasks using skills such as advance physical assessment requires more regular exposure to that skill. ${ }^{[42]}$ Consequently, new graduates should be provided every opportunity to relevant skill building activities and events.

While new graduates continue to report lack of support and working in difficult, complex, and high stress producing environments, the provision of adequate support leads to increased confidence. ${ }^{[36]}$ Support then, might include providing feedback at regular intervals regarding their performance. This might be as simple as having the opportunity to meet with others in order to self-check their decision making or evaluate their decisions in comparison with those decisions made by colleagues. ${ }^{[42]}$ Providing new graduates with supervision from knowledgeable and skilled colleagues might also enhance their level of confidence. To meet their learning needs and enhance confidence in their decision making ability, mentorship programs should evolve and reflect the dynamic needs of graduates as they advance through the stages of transition. ${ }^{[35]}$

In summary, the findings of this study seem to suggest that simply having mobile technologies at hand, while potentially helpful, is not enough. New graduates continue to have learning needs that might be met through professional development opportunities and meaningful interaction with colleagues.

\section{Limitations}

There were some limitations to this study. The sample size for this study was quite small. However, according to Johansson, Petersson, and Nilsson ${ }^{[16]}$ studies using mobile devices usually have a small number of participants due to the high cost for hardware and software. Conducting a longitudinal study also has inherent challenges in being able to retain study participants. While the participants in this study were provided access to the application free of charge for the duration of the study, the timing of the study, that is, during their transition from student to new graduate role, may have influenced the mortality rate of this study. To further deepen our understanding of the impact of mobile technologies on perceived clinical decision making, a comparison study between new and more experienced graduates is warranted. The findings though contribute towards expanding our under- 
standing of the transition students make to the new graduate role.

\section{Conclusions}

As stated at the outset, this study explored the impact of mobile technologies on new graduates' perceived clinical decision making and self-efficacy. Importantly the study concluded that over time, using mobile technologies at the point of care did not enhance the participants' perceived clinical decision making ability or self-efficacy. The transition shock associated with being an inexperienced new graduate significantly impacted levels of confidence and self-efficacy in decision-making over time.

Caution must be used when considering the findings of this study. It would be inappropriate to infer that mobile technologies at the point of care are unnecessary and potentially harmful. There are however, a variety of strategies one can use to help new graduates demonstrate higher levels of clini- cal decision-making and self-efficacy. There are professional development opportunities sites can use on a regular basis. Sites can create unit teams that regularly share experiences that encourage an exchange of ideas and insights that can inform future clinical decision-making. Setting up mentorship programs that pair experienced and novice nurses is useful. Herein, some of that transition shock can be supportively addressed, encouraging the novice to deepen and broaden his/her use of mobile technologies at the point of care.

In short, mobile technologies have much potential to improve the quality of nursing at the point of care. However, simply having the technology on hand is necessary but not sufficient. Education in specific ways to best use the technology accompanied by on-going professional development will better guarantee hospitals a more efficient return on their investments in mobile technologies.

\section{CONFlicts of InTEREST Disclosure}

The authors declare they have no conflicts of interest.

\section{REFERENCES}

[1] Lapinsky SE, Wax R, Showalter R, et al. Prospective evaluation of an internet-linked handheld computer critical care knowledge access system. Critical Care. 2004; 8. https://doi.org/10.1186/cc2967

[2] Koehler N, Vujovic O, McMenamin C. Healthcare professionals' use of mobile phones and the internet in clinical practice. Journal of Mobile Technology in Medicine. 2013; 2(1): 3-12. https: //doi.org/10.7309/jmtm.76

[3] Pesut DJ, Herman J. Clinical reasoning: The art and science of critical and creative thinking. Albany. NY: Delmar Publishers; 1999.

[4] Bandura A. Social foundations of thought and action: A social cognitive theory. Englewood Cliffs, N.J.: Prentice-Hall; 1986.

[5] Cheraghi F, Hassani P, Yaghmaei F, et al. Developing a valid and reliable self-efficacy in clinical performance scale. International Nursing Review. 2009; 56: 214-221. PMid: 19646171. https: //doi.org/10.1111/j.1466-7657.2008.00685.x

[6] Gilovich T, Keltner D, Nisbett RE. Social Psychology. New York, N.Y.: Norton; 2006. PMid: 16623688.

[7] Broussard BS, Broussard AB. Using electronic communication safely in health care settings. Nursing for Women's Health. 2013; 17(1): 59-62. PMid: 23399014. https://doi .org/10.1111/1751-486 X. 12007

[8] Qadri SS, Wang J, Ruiz JG, et al. Personal digital assistants as pointof-care tools in long-term care facilities: A pilot study. Educational Gerontology. 2009; 35: 294-305. https ://doi .org/10.1080/03 601270802467049

[9] Wyatt TH, Krasukopf PB, Gaylord NM, et al. Cooperative m-learning with nurse practitioner students. Nursing Education Perspectives. 2010; 31(2): 109-113. PMid: 20455369.

[10] Doran DM, Haynes RB, Kushniruk A, et al. Supporting evidencebased practice for nurses through information technologies. Worldviews on Evidence-Based Nursing First Quarter. 2010; 7(1): 4-
15. PMid: 20028493. https ://doi.org/10.1111/j.1741-678 $7.2009 .00179 . \mathrm{x}$

[11] Gautham M, Iyengar MS, Johnson CW. Mobile phone-based clinical guidance for rural health providers in India. Health Informatics Journal. 2015; 21(4): 253-266. https://doi.org/10.1177/146045 8214523153

[12] Hong HS, Kim IK, Lee SH, et al. Adoption of a PDA-based home hospice care system for cancer patients. CIN: Computers, Informatics, Nursing. 2009; 27(6): 365-371. https ://doi.org/10.1097/ NCN.0b013e3181bcab43

[13] Johansson P, Petersson G, Saveman B, et al. Using advanced mobile devices in nursing practice - the views of nurses and nursing students. Health Informatics Journal. 2014; 20(3): 220-231. PMid: 25183609. https://doi.org/10.1177/1460458213491512

[14] Turner CL, Casbard AC, Murphy MF. Barcode technology: Its role in increasing the safety of blood transfusion. Transfusion. 2003; 43(9): 1200-1209. PMid: 12919421. https://doi.org/10.1046/j.15 $37-2995.2003 .00428 \cdot \mathrm{x}$

[15] Chan JC, Chu RW, Young BW, et al. Use of an electronic barcode system for patient identification during blood transfusion: 3year experience in a regional hospital. Hong Kong Medical Journal. 2004; 10(3): 166-171. PMid: 15181220. Available from: http://jhi.sagepub.com

[16] Johansson PE, Petersson GI, Nilsson GC. Nursing students' experience of using a personal digital assistant (PDA) in clinical practice an intervention study. Nurse Education Today. 2013; 33(10): 12461251. PMid: 22999410. https://doi.org/10.1016/j.nedt.2 012.08 .019

[17] Mickan S, Atherton H, Roberts NW, et al. Use of handheld computers in clinical practice: A systematic review. BMC Medical Informatics and Decision Making. 2014; 14(56): 2-10. https: //doi.org/10.1186/1472-6947-14-56 
[18] Miller J, Shaw-Kokot JR, Arnold MS, et al. A study of personal digital assistants to enhance undergraduate clinical nursing education. Journal of Nursing Education. 2005; 44(1): 19-26. PMid: 15673170.

[19] Goldsworthy S, Lawrence N, Goodman W. The use of personal digital assistants at the point of care in an undergraduate nursing program. CIN: Computers, Informatics, Nursing. 2006; 24(3): 138-143. https://doi.org/10.1097/00024665-200605000-00009

[20] Pattilo RE, Brewer M, Smith C. Tracking clinical use of personal digital assistant reference resources. Nurse Educator. 2007; 32(1): 39-42. https://doi.org/10.1097/00006223-200701000-00011

[21] Hudson K, Buell V. Empowering a safer practice: PDAs are integral tools for nursing and health care. Journal of Nursing Management. 2011; 19: 400-406. PMid: 21507112. https://doi .org/10.111 $1 / j .1365-2834.2011 .01251 . x$

[22] Iverson L, Ball S, Harms A, et al. Technology in the college of nursing: Perception and use to achieve learning outcomes. Online Journal of Nursing Informatics. 2016; 20(1).

[23] Guo P, Watts K, Wharrad H. An integrative review of the impact of mobile technologies used by healthcare professionals to support education and practice. Nursing Open. 2015. Available from: http: //onlinelibrary.wiley.com/doi/10.1002/nop2.37/full

[24] Chioh MS, Yan CC, Tang KL, et al. The use of the personal digital assistant by nursing students in the classroom and clinical practice: A questionnaire survey. Singapore Nursing Journal. 2013; 40(20): $38-44$.

[25] Jamieson B, Secco L, Profit S, et al. An evidence-based pilot project: the influence of information-laden handheld computers on computer competence, information sources, and stress levels of nursing students. Canadian Journal of Nursing Informatics (CJNI). 2009; 4(4): 3-34.

[26] Wu P, Hwang G, Su L, et al. A context-aware mobile learning system for supporting cognitive apprenticeships in nursing skills training. Journal of Educational Technology \& Society. 2012; 15(1): 223-236. http://www.jstor.org/stable/jeductechsoci.15.1.223

[27] Kuiper R. Use of personal digital assistants to support clinical reasoning in undergraduate baccalaureate nursing students. CIN: Computers, Informatics, Nursing. 2008; 26(2): 90-98. Available from: www. journalmtm.com

[28] Sedgwick MG, Awosoga O, Grigg L, et al. A quantitative study exploring undergraduate nursing students' perception of their critical thinking and clinical decision making ability while using apps at the point of care. Journal of Nursing Education and Practice. 2016; 6(10): 1. https://doi.org/10.5430/jnep.v6n10p1

[29] Jenkins HM. Clinical decision making in nursing scale. In C. Feher Waltz \& L. Sherman Jenkins (Eds.) Measurement of Nursing Outcomes. NY: Springer; 2001. 33-40 p.

[30] Gorelick CS. Personal digital assistants: Their influence on clinical decision-making and the utilization of evidence-based practice in Baccalaureate nursing students (Unpublished doctoral dissertation). Duquesne University, Pittsburgh; 2010.
[31] Upton DR, Upton PM. Development of an evidence-based practice questionnaire for nurses. Journal of Advanced Nursing. 2006; 53(4): 454-458. PMid: 16448488. https://doi.org/10.1111/j.1365 $-2648.2006 .03739 . x$

[32] Rice K, Hwang J, Abrefa-Gyan T, et al. Evidence-based practice questionnaire: A confirmatory factor analysis in a social work sample. Advances in Social Work. 2010; 11(2): 158-173.

[33] Hagell A, Spencer L. An evaluation of an innovative audiotape method for keeping social care staff up to date with the latest research findings. Child and Family Social Work. 2004; 9: 187-196. https://doi.org/10.1111/j.1365-2206.2004.00313.x

[34] Bandura A. Regulation of cognitive processes through perceived self-efficacy. Developmental Psychology. 1989; 25: 729-735. https : //doi.org/10.1037/0012-1649.25.5.729

[35] Duchscher JEB. Transition shock: The initial stage of role adaptation for newly graduated registered nurses. Journal of Advanced Nursing. 2008.

[36] Gardiner I, Sheen J. Graduate nurse experiences of support: A review. Nurse Education Today. 2016; 40: 7-12. PMid: 27125143 https://doi.org/10.1016/j.nedt.2016.01.016

[37] Duchscher JEB. A process of becoming: The stages of new nursing graduate professional role transition. The Journal of Continuing Education in Nursing. 2008b; 39(10): 441-450. PMid: 18990890. https://doi.org/10.3928/00220124-20081001-03

[38] Duclos-Miller P. Successful graduate nurse transition: Meeting the challenge. Nurse Leader. 2011; 32-39. https ://doi .org/10.101 $6 / j . \mathrm{mnl} .2011 .05 .006$

[39] Gardin F. The "think-aloud" method to promote student modeling of expert thinking. Athletic Therapy Today. 2010; 15(4): 18-21. https://doi.org/10.1123/att.15.4.18

[40] Elder PR. Critical thinking competency standards. Dillon Beach, CA: The Foundation for Critical Thinking Press; 2007.

[41] Benner P, Sutphen M, Leonard V, et al. Educating Nurses. A Call for Radical Transformation. Stanford, CA: Jossey-Bass; 2010.

[42] Fry M, MacGregor C. Confidence and impact on clinical decisionmaking and behavior in the emergency department. Australasian Emergency Nursing Journal. 2014; 17: 91-97. PMid: 25113311. https://doi.org/10.1016/j.aenj . 2014.03.003

[43] Roberts K, Farrell G. Expectations and perceptions of graduates' performance at the start and at the end of their graduate year. Collegian. 2003; 10(2): 13-18. https://doi .org/10.1016/S1322-7 696 (08) 60049-9

[44] Taylor C. Assessing patient's needs: Does the same information guide expert and novice nurses? International Nursing Review. 2002; 49: 11-19. PMid: 11928932. https://doi.org/10.1046/j.14 $66-7657.2002 .00098 . x$

[45] Welk DS. Designing clinical examples to promote pattern recognition: Nursing education-based research and practical applications. Journal of Nursing Education. 2002; 41(2): 53-60. PMid: 11852984 